\title{
PENGARUH KEPEMIMPINAN TRANSFORMASIONAL PADA SINISISME TERHADAP PERUBAHAN ORGANISASIONAL DENGAN KEADILAN DISTRIBUTIF SEBAGAI PEMODERASI
}

\author{
Mega Asri Zona \\ Program Studi Manajemen Fakultas Ekonomi Universitas Negeri Padang
}

\begin{abstract}
This research used transformational leadership as independent variables which had negative influence on cynicism about organizational change. While distributive justice used as moderated variable that expected to affect the relationship of transformational leadership on cynicism about organizational change. The survey was conducted to 250 employees of PT PLN branch Padang (Rayon Kuranji, Rayon Tabing, Rayon Belanti and Rayon Indarung), PT Telkom area Padang, PT MNC Sky Vision (KPP KPP Padang and Bukittinggi). At least, 202 Questionnaires were collected, but only 187 questionnaires that can be processed.
\end{abstract}

Keywords: Cynicism about organizational change, transformational leadership, distributive justice

\section{PENDAHULUAN}

\section{Latar Belakang}

Organisasi memerlukan perubahan untuk menjamin terpenuhinya target kinerja yang sudah ada dan yang akan datang dengan lebih efektif dan efisien (Worren, Ruddle, \& Moore, 1999). Manajemen perubahan dibutuhkan untuk membantu organisasi dalam memadukan proses konsultasi manusia dengan intervensi teknis yang bertujuan untuk mengubah sistem dan struktur organisasi. Untuk menyukseskan program perubahan, manajemen perubahan memerlukan integrasi semua komponen yang ada di dalam organisasi, dan salah satu faktor yang paling penting adalah manusia. Sikap manusia, dalam hal ini karyawan, terhadap perubahan, berpengaruh signifikan pada perilaku yang ditunjukkan selama perubahan itu berlangsung (Vakola, Tsaousis, \& Nikolaou, 2004). Dalam penelitian tersebut dikemukakan bahwa respon karyawan terhadap perubahan dapat dilihat dari sikap yang paling positif (optimis dan tertarik terhadap keberhasilan program perubahan) ke sikap yang paling negatif (penolakan terhadap perubahan). Akan tetapi, Cameron (2008) menyebutkan bahwa sifat dasar manusia akan bereaksi lebih kuat terhadap hal yang bersifat negatif. Jadi, setiap kali organisasi mengadakan perubahan, maka tujuan positif perubahan akan selalu dibayangi oleh respon negatif yang mengarah kepada niat menolak perubahan. Salah satu sikap yang menjadi prediktor dari niat untuk menolak perubahan organisasional adalah sinis.

Sinisisme merupakan sikap paling negatif yang bisa ditunjukkan oleh seorang karyawan terhadap organisasi (Dean, Branders, \& Dharwadkar, 1998). Akan tetapi, karyawan tidak bisa hanya dibagi menjadi karyawan yang sinis dan tidak sinis, dikarenakan setiap karyawan mempunyai tingkat sinis yang beragam. Sinisisme pada tingkat yang rendah tidak terlalu berdampak pada perubahan, berbeda dengan sinisisme pada tingkat yang lebih tinggi, yang akan berdampak 
pada proses dan hasil program perubahan (Vance, Brooks, \& Tesluk, 1996; McClough, Rogelberg, Fisher, \& Bachiochi, 1998).

Menurut Reichers, Wanous, dan Austin (1997) sinisisme yang tinggi menyebabkan rendahnya komitmen, kepuasan dan motivasi kerja karyawan. Efek langsung yang bisa dilihat adalah meningkatnya absensi dan keluhan karyawan serta menurunnya produktivitas kerja individu. Selanjutnya, McClough et al. (1998) menemukan bahwa sinisisme mengurangi kualitas pekerjaan karyawan. Wanous, Reichers, dan Austin (2000) mengasosiasikan sinisisme terhadap perubahan organisasional dengan berbagai perilaku negatif, diantaranya tingkat absensi yang tinggi, meningkatnya keluhan, kinerja yang rendah, dan keinginan untuk keluar dari organisasi. Stanley, Meyer, dan Topolnytsky (2005) mengemukakan bahwa sinisisme berpengaruh pada penolakan terhadap perubahan organisasional. Karyawan yang yakin bahwa agen perubahan yang terlibat memiliki berbagai alasan diluar alasan yang disebutkannya tidak akan bersedia untuk mendukung perubahan.

Penelitian ini mengikuti konsep yang dikemukakan oleh Reichers et al. (1997), dan kemudian disempurnakan lagi pada penelitian tahun 2000, yang mendefinisikan sinisisme terhadap perubahan organisasional sebagai pandangan yang pesimis mengenai kesuksesan upaya perubahan karena yang bertanggung jawab terhadap perubahan dinilai tidak memiliki motivasi, tidak kompeten, atau gabungan dari keduanya. Wanous et al. (2000) melanjutkan penelitian sebelumnya (Reichers et al., 1994 \& 1997), berdasarkan hasil confirmatory factor analysis (CFA), menyimpulkan bahwa sinisisme terhadap perubahan organisasional terdiri atas dua komponen, yaitu pesimisme dan dispositional attribution. Pesimisme terhadap keberhasilan dari program perubahan disebabkan oleh sejarah perubahan organisasi di masa lalu yang tidak sepenuhnya sukses (Reichers et al., 1997). Jadi, ketika organisasi mengadakan perubahan lagi, maka akan muncul pesimisme dalam diri karyawan terhadap kemungkinan keberhasilan dari perubahan tersebut. Pesimisme dijelaskan melalui expectancy theory (teori pengharapan) yang dikembangkan oleh Vroom. Kepercayaan bahwa usaha yang diberikan untuk menyukseskan perubahan kurang optimal dan sejarah perubahan yang dilakukan oleh organisasi yang tidak sepenuhnya sukses menyebabkan pesimisme terhadap perubahan organisasional (Wanous et al., 2000). Dispositional attribution diperoleh berdasarkan attribution theory (teori atribusi) yang dikembangkan oleh Jones dan Davis (dalam Wanous et al., 2000). Teori ini relevan dikarenakan konstruk sinisisme terhadap perubahan organisasional memperhatikan penilaian seseorang terhadap akibat dari perilaku orang lain. Dispositional attribution menyangkut penilaian karyawan yang menyalahkan kegagalan kepada seseorang yang dianggap bertanggung jawab terhadap perubahan.

Dalam proses perubahan, seorang pemimpin memainkan peranan yang sangat penting melalui pengelolaan hubungan, mengkoordinasikan mekanisme perubahan, menyesuaikan kegiatan operasional dengan strategi, membangun struktur dan mengembangkan penghargaan (Weisbord, 1976 dalam Bommer, Rich, \& Rubin, 2005). Proses perubahan memerlukan kepemimpinan yang fleksibel seperti kepemimpinan transformasional (Reardon, Reardon, \& Rowe, 1998). Selain itu menurut Richardson dan Vandenberg (2005) kepemimpinan transformasional juga dapat mempengaruhi reaksi karyawan terhadap perubahan. Efek motivasional dari kepemimpinan transformasional merupakan dasar bagi pemimpin untuk mempengaruhi karyawan agar dapat bekerja melebihi harapan terhadap mereka demi kepentingan organisasi (Shamir, House, \& Arthur, 1993). Hal tersebut nantinya 
mengarahkan karyawan terindentifikasi lebih kuat dengan organisasi dan pada akhirnya menimbulkan keinginan yang lebih besar untuk berkontribusi dalam program perubahan organisasional. Selanjutnya Wu, Neubert, dan Yi (2007) menjelaskan bahwa kepemimpinan transformasional membuat karyawan lebih termotivasi untuk terlibat dalam perubahan organisasional melalui penggambaran visi yang jelas.

Penerapan kepemimpinan transformasional di organisasi, terutama yang sedang mengalami perubahan, akan lebih efektif bila didukung oleh adanya kepercayaan yang ditimbulkan oleh keadilan distributif (distributive justice) (Kickul, Lester, \& Finki, 2002; Melkonian, 2004; Warner, Hegtvedt \& Roman, 2005; Wu, Neubert \& Yi, 2007; Bernerth, Armenakis, Field, \& Walker, 2007). Keadilan distributif merupakan keadilan terhadap hasil yang diterima oleh karyawan.

Dalam penelitiannya, Bernerth et al. (2007) menemukan bahwa keadilan distributif berpengaruh pada reaksi karyawan terhadap perubahan organisasional. Persepsi karyawan terhadap ketidakadilan yang terjadi di organisasi selama proses perubahan berlangsung akan membentuk sikap penolakan terhadap program perubahan itu sendiri (Kickul et al., 2002). Hal ini dikarenakan sebagian besar usaha perubahan diasosiasikan dengan ketidakpastian, sehingga karyawan merasa bingung dengan peran mereka dalam perubahan. Pendapat ini didukung oleh Bommer et al. (2005), yang dalam penelitiannya mengemukakan bahwa penerapan kepemimpinan transformasional pada saat terjadi perubahan harus didukung oleh iklim organisasional, salah satunya keadilan distributif. Hal ini dikarenakan pada saat terjadi perubahan, terdapat ketidakpastian yang menyebabkan individu sangat sensitif menyangkut keadilan distributif. Kepemimpinan transformasional bertujuan untuk membangun kepercayaan karyawan (Bommer et al., 2005). Pengembangan dimensi keadilan distributif dapat membantu kepemimpinan transformasional dalam membangun kepercayaan tersebut.

Pillai, Scandura, dan Williams (1999) mengemukakan bahwa keadilan distributif dapat menciptakan iklim organisasional yang memungkinkan penerapan kepemimpinan transformasional menjadi lebih efektif. Oleh karena itu, keadilan distributif dalam penelitian ini diharapkan dapat memperkuat pengaruh negatif kepemimpinan transformasional pada sinisisme terhadap perubahan organisasional.

Paling tidak terdapat dua penelitian yang menggunakan kepemimpinan transformasional sebagai anteseden sinisisme terhadap perubahan organisasional, yaitu penelitian Bommer et al. (2005) dan Wu et al. (2007). Penelitian Bommer et al. (2005) menggunakan studi longitudinal untuk mengukur pengaruh kepemimpinan transformasional pada sinisisme terhadap perubahan organisasional. Menurut Rindfleisch, Malter, Ganesan, dan Moorman (2008), studi longitudinal tidak selalu baik untuk sebuah penelitian. Pada beberapa kasus, penggunaan data cross sectional masih lebih baik, contohnya pada penelitian mengenai sinisisme terhadap perubahan organisasional. Kedua elemen sinisisme, yaitu pesimisme dan dispositional attribution hanya bisa diukur ketika hasil dari perubahan belum kelihatan. Pesimisme terhadap keberhasilan progam perubahan hanya bisa dilihat ketika perubahan baru terjadi. Dispositional attribution yang mengacu kepada kecenderungan meragukan kemampuan dan motivasi dari agen perubahan juga hanya bisa dilihat pada tahap awal perubahan. Penggunaan studi longitudinal pada penelitian sinisisme terhadap perubahan organisasional juga dikhawatirkan dapat memunculkan peristiwa yang dapat mengintervensi varian variabel sinisisme 
selama perubahan berlangsung. Selain itu, responden yang digunakan pada penelitian awal tidak semuanya bisa disertakan kembali pada penelitian selanjutnya. Hal tersebut bisa menyebabkan hasil penelitian mengenai sinisisme menjadi bias.

Selanjutnya, penelitian $\mathrm{Wu}$ et al. (2007) sebelumnya telah membuktikan bahwa kepemimpinan transformasional berpengaruh negatif pada sinisisme terhadap perubahan organisasional. Penelitian ini juga menyimpulkan bahwa penerapan kepemimpinan transformasional dalam organisasi yang sedang mengadakan perubahan perlu didukung oleh iklim organisasional. Iklim organisasional yang paling sering dikaitkan dengan sinisisme terhadap perubahan organisasional adalah keadilan distributif (Kickul et al., 2002; Melkonian, 2004; Warner et al., 2005; Wu et al., 2007; Bernerth et al., 2007). Hal ini dikarenakan pada saat terjadi perubahan, terdapat ketidakpastian yang menyebabkan individu sangat sensitif menyangkut keadilan distributif.

Keadilan distributif digunakan sebagai variabel pemoderasi dikarenakan beberapa penelitian menunjukkan bahwa variabel ini dapat memperkuat pengaruh kepemimpinan transformasional pada reaksi karyawan terhadap perubahan organisasional (Pillai, Scandura, \& Williams, 1999; Simons \& Roberson, 2003). Berdasarkan uraian diatas, maka peneliti mencoba melihat pengaruh kepemimpinan transformasional pada sinisisme terhadap perubahan organisasional dengan keadilan distributif sebagai variabel pemoderasi.

\section{TINJAUAN PUSTAKA}

\section{Kepemimpinan Transformasional dan Sinisisme terhadap Perubahan Organisasional}

Bass (1990) mendefinisikan kepemimpinan transformasional sebagai kepemimpinan yang memperluas dan meningkatkan keterlibatan karyawan, menghasilkan kesadaran dan penerimaan terhadap tujuan dan misi organisasi, dan mendorong karyawan untuk melihat melampaui kepentingan dirinya sendiri demi kebaikan organisasi. Penelitian tersebut merinci kepemimpinan transformasional dalam empat karakteristik, yaitu pertimbangan individual, stimulasi intelektual, motivasi yang menginspirasi, dan karisma. Pertimbangan individual menjelaskan bahwa seorang pemimpin transformasional memperlihatkan perhatian kepada pengikutnya, memperlakukan mereka sebagai individu, mengenal pengikutnya, mendengarkan dan mempertimbangan ide-ide mereka. Stimulasi intelektual berkaitan dengan mendorong kemampuan intelejensi, rasionalitas, dan pemecahan masalah individu dengan hati-hati. Motivasi yang menginspirasi menjelaskan bahwa seorang pemimpin transformasional mempunyai kemampuan untuk memotivasi pengikutnya agar memberikan kinerja yang luar biasa. Hal ini juga berkaitan dengan cara mengkomunikasikan ekspektasi yang tinggi dan menjelaskan tujuan yang penting dengan cara yang sederhana. Selanjutnya, Karisma, yang sering juga disebut pengaruh yang ideal, menjelaskan bagaimana seorang pemimpin menjadi acuan untuk orang-orang di sekitarnya. Karakteristik ini berkaitan dengan memberikan arahan yang jelas, menanamkan kebanggaan dan meraih kepercayaan serta rasa hormat.

Wanous et al. (2000) menjelaskan mengenai sinisisme terhadap perubahan organisasional dengan menggunakan expectancy theory (teori pengharapan) yang 
dikembangkan oleh Vroom. Teori pengharapan meyakini perubahan merupakan hasil usaha pribadi. Kerangka pemikiran seperti ini menjelaskan asumsi karaywan bahwa kesuksesan perubahan organisasional bergantung pada usaha orang yang bertanggung jawab terhadap perubahan tersebut. Hal ini mencerminkan harapan terhadap seseorang. Ketika orang yang bertanggung jawab terhadap perubahan tersebut dinilai tidak mempunyai kompetensi yang dibutuhkan atau kurang motivasi, maka hal ini akan menimbulkan pesimisme terhadap hasil dari perubahan (Reichers et al., 1997; Dean et al., 1998; Wanous et al., 2000; Wu et al., 2007).

Teori ini mengemukakan bahwa seseorang akan memilih untuk bersikap atau bertindak dalam cara tertentu karena mereka termotivasi untuk memilih perilaku tertentu berdasarkan hasil yang mereka harapkan dari perilaku tersebut. Pada dasarnya pemilihan perilaku tersebut akan ditentukan berdasarkan keinginan dari hasil yang akan diperoleh. Inti dari teori ini adalah proses kognitif menyangkut bagaimana individu memproses elemen motivasi yang berbeda. Teori pengharapan berbicara tentang proses mental terkait pilihan (Wanous et al., 2000). Dalam teori ini dijelaskan proses seorang individu membuat sebuah keputusan.

Selanjutnya, Wanous et al. (2000) juga mengemukakan teori atribusi yang berkaitan dengan sinisisme terhadap perubahan organisasional. Teori atribusi ini mencoba menjelaskan penyebab suatu kejadian. Lebih lanjut, teori atribusi merupakan teori motivasi yang melihat bagaimana rata-rata orang mengartikan sebuah peristiwa berdasarkan alasannya untuk menemukan penyebab sesuai dengan lingkungan pengetahuannya. Teori ini pada dasarnya melihat bagaimana seseorang memahami dunianya, penyebab suatu peristiwa dan mereka kemudian menyimpulkan pengaruh yang dibuat mengenai perilaku orang lain dan diri mereka sendiri. Seseorang yang sinis terhadap perubahan organisasional, biasanya menolak untuk ikut terlibat dalam perubahan (Reichers et al., 1997). Oleh karena itu, semua hal yang terjadi selama proses perubahan diasumsikan sebagai akibat tunggal dari tindakan agen perubahan.

Reardon et al. (1998) mengemukakan bahwa pada saat terjadi perubahan, diperlukan seorang pemimpin yang bisa menyampaikan maksud dan tujuan perubahan dengan tepat. Selain itu, seorang pemimpin diharuskan memberikan wawasan dan membagi otoritas pada saat terjadi perubahan. Pemimpin pada saat perubahan akan lebih efektif jika mereka bisa menginspirasi orang lain untuk mengadaptasi program perubahan yang diterapkan. Bommer et al. (2005) mengemukakan bahwa seorang pemimpin mempunyai peranan yang penting selama proses perubahan berlangsung. Ketika karyawan merasa bahwa program perubahan dapat memberikan nilai tambah, maka mereka akan cenderung ingin terlibat dalam proses perubahan. Hal ini membuat karyawan berusaha agar perubahan tersebut bisa mencapai tujuan yang diharapkan jika mereka memberikan usaha yang lebih baik. Tindakan ini selanjutnya membuat karyawan optimis terhadap program perubahan, yang nantinya diharapkan berpengaruh negatif pada sinisisme terhadap perubahan organisasional (Wu et al., 2007).

Ketika karyawan merasa sebagai bagian dari perubahan organisasional dan terlibat di dalamnya, maka ia tidak akan melihat perubahan sebagai tindakan dari satu pihak saja, dalam hal ini agen perubahan. Berdasarkan teori atribusi, maka keberhasilan perubahan dianggap sebagai tanggung jawab bersama keseluruhan organisasi. Karyawan sebagai bagian organisasi akan berupaya lebih keras agar perubahan tersebut bisa mencapai tujuan yang telah ditetapkan demi kepentingan 
bersama. Oleh karena itu, kepemimpinan transformasional diharapkan dapat membantu mengurangi sinisisme karyawan terhadap perubahan organisasional.

Hipotesis 1: Kepemimpinan transformasional berpengaruh negatif pada sinisisme terhadap perubahan organisasional

\section{Keadilan Distributif sebagai Pemoderasi}

Keadilan distributif mengacu kepada keadilan yang diterima oleh karyawan dari organisasi terkait hasil (Moorman, 1991). Kebanyakan riset mengenai keadilan distributif mengacu kepada penelitian Adam (dalam Colquitt et al., 2001) yang menjelaskan bahwa konsep keadilan distributif mengacu kepada teori keadilan. Teori ini mengemukakan bahwa karyawan membandingkan rasio dari usaha yang diberikan dengan hasil yang diperolehnya dengan usaha dan hasil yang diperoleh oleh orang lain (Kwon et al., 2008). Jika karyawan merasa bahwa rasio perbandingannya tidak adil, maka mereka akan mengupayakan untuk pemulihan keadilan.

Seseorang yang sinis percaya bahwa keadilan tidak terlaksana di lingkungan pekerjaannya (Brown \& Cregan, 2008). Berdasarkan teori keadilan dan teori pertukaran sosial, karyawan tidak akan menunjukkan sikap yang sinis mengenai perubahan organisasional apabila mereka menganggap bahwa rasio dari input yang mereka berikan dan hasil yang mereka peroleh sama dengan rasio dari input dan hasil dari orang lain dalam organisasi tersebut.

Jika terjadi perubahan, dengan adanya distribusi keadilan, maka karyawan tetap tidak akan mengurangi upaya yang mereka berikan. Karyawan akan lebih ingin terlibat dalam proses perubahan ketika keadilan distributif telah terlaksana. Mereka akan memberikan usaha dan komitmen untuk menyukseskan program perubahan dikarenakan mereka merasa perubahan yang terjadi tidak akan mengurangi hak mereka di organisasi. Dengan kondisi keadilan distributif yang terlaksana, kepemimpinan transformasional akan lebih bisa menjalankan perannya untuk mempengaruhi penerimaan karyawan terhadap perubahan. Hal ini nantinya diharapkan dapat memperkuat pengaruh negatif kepemimpinan transformasional pada sinisisme terhadap perubahan organisasional.

Hipotesis 2: Keadilan distributif memoderasi pengaruh negatif kepemimpinan transformasional pada sinisisme terhadap perubahan organisasional. Semakin tinggi keadilan distributif, maka pengaruh negatif kepemimpinan transformasional pada sinisisme terhadap perubahan organisasional akan semakin kuat.

\section{Model Penelitian}

Kepemimpinan transformasional berpengaruh negatif pada sinisisme terhadap perubahan organisasional yang dimoderasi oleh keadilan organisasional (keadilan distributif, keadilan prosedural, dan keadilan interaksional). Model penelitian ditunjukkan oleh gambar 1 di bawah. 
Gambar 1

Model Penelitian

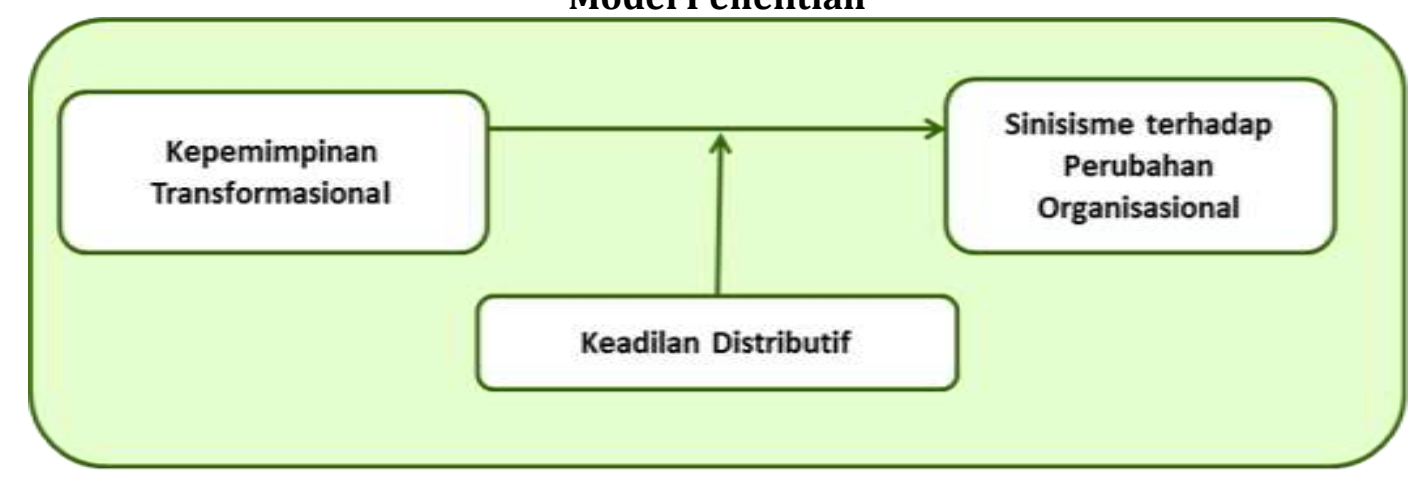

METODE PENELITIAN

\section{Desain dan Sampel}

Desain penelitian yang digunakan adalah studi konfirmatori (confirmatory $s t u d y$ ) dengan pengujian hipotesis. Perubahan organisasional merupakan fenomena sosial yang akan ditangkap dan bisa digeneralisasi dengan lebih baik jika menggunakan metode survei (Kerlinger \& Lee, 2000).

Sampel yang digunakan adalah PT PLN cabang Padang (Rayon Kuranji, Rayon Tabing, Rayon Belanti, dan Rayon Indarung), PT Telkom area Padang, PT MNC Sky Vision (KPP Padang dan KPP Bukittinggi). Penyampelan dilakukan dengan menggunakan metode purposive sampling.

\section{Pengukuran}

Variabel-variabel yang digunakan dalam penelitian ini adalah sinisisme terhadap perubahan organisasional sebagai variabel terikat $(\mathrm{Y})$, sedangkan kepemimpinan transformasional sebagai variabel bebas (X), dengan keadilan distributif sebagai variable pemoderasi (Z).

Sinisisme terhadap Perubahan Organisasional. Menurut Wanous et al. (2000), sinisisme terhadap perubahan organisasional dapat didefinisikan sebagai pandangan yang pesimis mengenai kesuksesan dari upaya perubahan dikarenakan yang bertanggung jawab terhadap perubahan dinilai tidak memiliki motivasi, tidak kompeten, atau gabungan dari keduanya. Penelitian ini menggunakan 8 item pernyataan yang dikembangkan oleh Reichers, Wanous dan Austin $(1994,1997$, 2000) untuk mengukur sinisisme terhadap perubahan organisasional.

Kepemimpinan Transformasional. Menurut Bass (1990), kepemimpinan transformasional adalah kepemimpinan yang memperluas dan meningkatkan kepentingan karyawan, menghasilkan kesadaran dan penerimaan terhadap tujuan dan misi organisasi, dan mendorong karyawan untuk melihat melampaui kepentingan dirinya sendiri demi kebaikan organisasi. Dalam penelitian ini kepemimpinan transformasional diukur menggunakan 20 item pernyataan multifactor leadership questionnaire (MLQ) yang dikembangkan oleh Bass dan Avolio (1995).

Keadilan Distributif. Keadilan organisasional adalah persepsi keadilan yang dirasakan oleh karyawan dalam lingkungan kerjanya terkait hasil yang 
diperoleh (Moorman, 1991). Keadilan distributif diukur menggunakan 5 item pernyataan yang dikembangkan oleh Moorman (1991).

\section{Analisis}

Untuk menguji hipotesis, data yang diperoleh dari hasil penelitian akan dianalisis menggunakan moderated regression analysis. Moderated regression analysis dilakukan untuk menguji dampak simultan dari variabel bebas pada variabel terikat dengan menggunakan variabel moderasi. Apabila variabel moderasi signifikan, maka moderasi memperkuat pengaruh variabel bebas pada variabel terikat.

\section{HASIL PENELITIAN DAN PEMBAHASAN}

\section{Penyebaran Kuesioner}

Kuesioner yang disebarkan sebanyak 250 kuesioner kepada responden yang merupakan karyawan di PT PLN cabang Padang (Rayon Kuranji, Rayon Tabing, Rayon Belanti, dan Rayon Indarung), PT Telkom area Padang, PT MNC Sky Vision (KPP Padang dan KPP Bukittinggi). Kuesioner yang terkumpul sebanyak 202 kuesioner, namun hanya 187 kuesioner yang dapat diolah.

Tabel 1 menunjukkan mean, standar deviasi, dan koefisien korelasi antar variabel. Hasil pengolahan data statistik deskriptif menunjukkan bahwa kepemimpinan transformasional berhubungan negatif dan signifikan dengan sinisisme terhadap perubahan organisasional $(\mathrm{r}=-0.390 ; p<0,01)$. Penerapan kepemimpinan transformasional berhubungan dengan sinisisme terhadap perubahan organisasional. Selain itu, keadilan distributif $(r=-0,178 ; p<0,05)$, berhubungan negatif dan signifikan dengan sinisisme terhadap perubahan organisasional. Keadilan distributif di tempat kerja akan berhubungan dengan respon karyawan terhadap perubahan yang terjadi di organisasi.

\section{Tabel 1}

Mean, Standar Deviasi, Dan Koefisien Korelasi Antar Variabel

\begin{tabular}{cccccc}
\hline Variabel & M & SD & KT & KD & STOP \\
\hline KT & 3,5527 & 0,60361 & & & \\
KD & 3,4043 & 0,75119 & $0,613^{* *}$ & & \\
STPO & 2,6678 & 0,88569 & $-0,390^{* *}$ & $-0,178^{*}$ & \\
\hline$* P<0.05$ & & & & & \\
$* * P<0.01$ & & & & &
\end{tabular}

\section{Ringkasan Hasil Pengujian Hipotesis}

Hipotesis 1 menyatakan bahwa kepemimpinan transformasional berpengaruh negatif pada sinisisme terhadap perubahan organisasional. Hasil pengujian hipotesis menunjukkan bahwa kepemimpinan transformasional berpengaruh negatif dan signifikan pada sinisisme terhadap perubahan organisasional $(ß=-0,390 ; t=-5,758 ; p<0,01)$. Hasil ini mendukung hipotesis 1 . Selanjutnya, hipotesis 2 menyatakan bahwa keadilan distributif memoderasi pengaruh negatif kepemimpinan transformasional pada sinisisme terhadap perubahan organisasional. Semakin tinggi keadilan distributif, maka pengaruh 
negatif kepemimpinan transformasional pada sinisisme terhadap perubahan organisasional akan semakin kuat. Hasil pengujian hipotesis 2 menunjukkan bahwa keadilan distributif tidak memperkuat pengaruh negatif kepemimpinan transformasional pada sinisisme terhadap perubahan organisasional $(ß=1,747 ; t=$ 2,093; $p<0,05$ ). Ini berarti hipotesis 2 tidak didukung. Tabel 2 menunjukkan hasil pengujian hipotesis secara keseluruhan.

Tabel 2

Hasil Pengujian Hipotesis

\begin{tabular}{|c|c|c|c|}
\hline & \multicolumn{3}{|c|}{$\begin{array}{c}\text { Sinisisme terhadap Perubahan } \\
\text { Organisasional }\end{array}$} \\
\hline & $\mathbf{B}$ & $\mathbf{t}$ & Sig. \\
\hline \multicolumn{4}{|l|}{ Step 1} \\
\hline Kepemimpinan Transformasional (KT) & $-0,390$ & $-5,758$ & $0,000^{*}$ \\
\hline \multicolumn{4}{|l|}{$\mathrm{R}^{2}=0,152^{* *}$} \\
\hline \multicolumn{4}{|l|}{ Step 2} \\
\hline Kepemimpinan Transformasional (KT) & $-0,352$ & $-3,238$ & $0,001^{* *}$ \\
\hline Keadilan Distributif (KD) & 0,176 & 1,683 & 0,094 \\
\hline \multicolumn{4}{|l|}{ Step 3} \\
\hline Kepemimpinan Transformasional (KT) & $-0,312$ & $-0,985$ & 0,339 \\
\hline Keadilan Distributif (KD) & $-0,923$ & $-1,724$ & 0,087 \\
\hline KT X KD & 1,747 & 2,039 & $0,043^{*}$ \\
\hline
\end{tabular}

\section{PEMBAHASAN}

Dengan penerapan kepemimpinan transformasional, karyawan diharapkan dapat melihat perubahan sebagai sesuatu yang positif, dan hal ini nantinya dapat mengurangi sinisisme terhadap perubahan organisasional. Hasil pengujian dalam penelitian ini mendukung pengaruh langsung kepemimpinan transformasional pada sinisisme terhadap perubahan organisasional. Akan tetapi, interaksi kepemimpinan transformasional dengan keadilan distributif tidak memperkuat pengaruh negatif kepemimpinan transformasional pada sinisisme terhadap perubahan organisasional.

Hipotesis 1 yang menyatakan bahwa kepemimpinan transformasional berpengaruh negatif pada sinisisme terhadap perubahan organisasional, didukung. Hasil ini sesuai dengan penelitian yang dilakukan oleh Bommer et al. (2005) dan Wu et al. (2007). Menurut $\mathrm{Wu}$ et al. (2007), kepemimpinan transformasional mendorong karyawan untuk terlibat dalam proses perubahan organisasional. Melalui pernyataan visi yang jelas, dan membantu karyawan untuk menyesuaikan diri dengan organisasi, pemimpin transformasional bisa mendorong peningkatan motivasi karyawan untuk terlibat dalam organisasi.

Menurut Bommer et al. (2005), penerapan kepemimpinan transformasional yang efektif pada saat terjadi perubahan akan membantu mengatasi sinisisme terhadap perubahan organisasional. Karyawan dikatakan akan bersikap lebih 
terbuka dan berkomitmen terhadap perubahan yang terjadi. Melalui penerapan kepemimpinan transformasional, karyawan dapat melihat sisi positif dari suatu perubahan yang bisa bermanfaat bagi mereka (Wu et al., 2007). Ketika karyawan merasa bahwa program perubahan dapat memberikan nilai tambah, maka mereka akan cenderung ingin terlibat dalam proses perubahan, dan berusaha agar perubahan tersebut bisa mencapai tujuan yang diharapkan ketika mereka memberikan usaha yang lebih baik. Hal ini selanjutnya mengarahkan karyawan kepada penerimaan terhadap program perubahan, yang berpengaruh negatif pada sinisisme terhadap perubahan organisasional.

Karyawan yang merasa sebagai bagian dari perubahan organisasi dan terlibat di dalamnya, tidak akan melihat perubahan sebagai tindakan dari satu pihak saja, dalam hal ini agen perubahan. Berdasarkan teori atribusi, maka perubahan dianggap sebagai tanggung jawab bersama keseluruhan organisasi. Oleh karena itu, agen perubahan tidak akan dianggap sebagai satu-satunya pihak yang bersalah jika perubahan organisasional tidak mencapai hasil yang diharapkan.

Selanjutnya, hasil pengujian hipotesis 2 yang menyatakan keadilan distributif memoderasi pengaruh negatif kepemimpinan transformasional pada sinisisme terhadap perubahan organisasional, tidak didukung. Keadilan distributif berfokus pada rasio dari hasil yang diterima oleh seseorang. Menurut teori keadilan yang dikemukakan oleh Adam, individu mempunyai kecenderungan untuk membandingkan rasio dari input yang mereka berikan pada organisasi dan hasil yang mereka terima dengan input dan hasil yang diterima oleh orang lain (Bolino \& Turnley, 2008). Jika individu merasa bahwa rasionya tidak setara, teori ini berpendapat bahwa individu tersebut akan merancang tindakan untuk memulihkan keadilan. Berbagai sikap yang nantinya akan melandasi perilaku negatif muncul sebagai akibat persepsi karyawan terhadap ketidakadilan rasio hasil yang mereka peroleh dibandingkan dengan orang lain dalam organisasi.

Penemuan menarik dalam penelitian ini bahwa keadilan distributif memperlemah pengaruh negatif kepemimpinan transformasional pada sinisisme terhadap perubahan organisasional. Bolino dan Turnley (2008) mengemukakan bahwa model orientasi nilai dalam konteks budaya dapat mempengaruhi bagaimana karyawan mengkonseptualisasikan input dan hasil, perbandingan dengan orang lain, acuan terhadap keadilan, dan reaksi mereka terhadap ketidakadilan. Untuk Indonesia yang budayanya lebih mengacu kepada kolektivisme, Erdogan dan Liden (2006) mengemukakan bahwa kolektivisme tersebut mempengaruhi respon karyawan terhadap keadilan organisasional. Hal ini membuat konteks keadilan lebih mengacu kepada persamaan hasil yang diperoleh, tanpa adanya perbandingan dari input yang diberikan kepada organisasi. Oleh karena itu, penerapan teori keadilan pada keadilan distributif tidak sesuai. Persepsi adil dalam budaya kolektivisme mengacu pada model communal sharing, yang memperlakukan anggota dalam kelompok sama tanpa mempertimbangkan kontribusinya terhadap organisasi (Amborse \& Kulik, 1999). Berdasarkan penjelasan di atas, jika keadilan yang sesuai dengan teori keadilan diterapkan, karyawan justru akan menganggap hal tersebut tidak adil. Hal ini nantinya akan memperlemah pengaruh negatif kepemimpinan transformasional pada sinisisme terhadap perubahan organisasional.

Penelitian Chen (1995), Deutsch (1975), Gergen et al. (1980) menemukan bahwa individu di negara di luar konteks Amerika lebih mengutamakan persamaan dalam hasil yang mereka peroleh dibandingkan dengan keadilan. Penjelasan tersebut berpengaruh terhadap penelitian ini, dimana setiap anggota dalam 
organisasi lebih mengutamakan persamaan hasil yang mereka peroleh dibandingkan dengan keadilan dari hasil tersebut.

Dalam penelitiannya, Bolino dan Turnley (2008) juga mengemukakan bahwa budaya dan orientasi nilai individu berpengaruh terhadap cara mereka memandang keadilan. Oleh karena itu, hasil dalam penelitian ini menemukan bahwa keadilan distributif akan memperlemah pengaruh negatif kepemimpinan transformasional pada sinisisme terhadap perubahan organisasional.

\section{Implikasi Penelitian}

Secara teoritis, penelitian ini mengkonfirmasi faktor yang memperkuat atau memperlemah pengaruh negatif kepemimpinan transformasioanl pada sinisisme terhadap perubahan organisasional, dengan menggunakan keadilan distributif sebagai pemoderasi. Hasil penelitian memperlihatkan bahwa keadilan distributif memperlemah pengaruh negatif kepemimpinan transformasional padda sinisisme terhadap perubahan organisasional. Selain itu, penggunaan studi cross-sectional dianggap tepat untuk melihat sinisisme terhadap perubahan organisasional.

\section{KESIMPULAN DAN SARAN}

Pengambilan sampel dalam penelitian ini menggunakan teknik purposive sampling (non-random sampling), sehingga generalisasi hasil penelitian harus dilakukan secara hati-hati. Oleh karena itu, penelitian mendatang sebaiknya menggunakan teknik random sampling, sehingga tingkat generalisasi hasil penelitian lebih tinggi.

Common method bias. Penggunaan self-report data untuk menilai sinisisme terhadap perubahan organisasional kurang mampu memberikan laporan yang akurat dan cenderung bias terkait sensitivitas sosial variabel yang digunakan dalam penelitian. Akan tetapi penelitian ini telah mencoba untuk mengurangi bias tersebut dengan tidak menyebutkan nama variabel sinisisme terhadap perubahan organisasional dalam kuesioner yang disebarkan.

Penelitian yang dilakukan menggunakan metode survei dengan desain korelasional, sehingga kurang mampu menjelaskan hubungan kausal antar variabel yang diteliti. Penelitian mendatang sebaiknya menggunakan desain eksperimental, sehingga lebih dapat menjelaskan hubungan kausal dari variabel yang diteliti.

\section{DAFTAR PUSTAKA}

Albrecht, S. L., \& Andreetta, M. 2011. The Influence of Empowering Leadership, Empowerment and Engagement on Affective Commitment and Turnover Intentions in Community Health Service Worker. Leadership in Health Service, 24 (3): 228-237.

Anderson, D., \& Anderson, L. A. 2010. Beyond Change Management: How to Achieve Breakthrough Result through Conscious Change Leadership, $2^{\text {nd }}$ Edition. Pfeiffer: Wiley.

Andersson, L. M. 1996. Employee Cynicism: An Examination Using Contract Violation Framework. Human Relations, 49: 1359-1418.

Andersson, L. M., \& Bateman, T. S. 1997. Cynicism in Workplace: Some Causes and Effects. Journal of Organizational Behavior, 18: 449-469. 
Armenakis, A. A., Harris, S. G., \& Mossholder, K. W. 1993. Creating Readiness for Organizational Change. Human Relations, 46: 681-703.

Awan, M. R., \& Mahmood, K. 2010. Relationship among Leadership Style, Organizational Culture and Employee Commitment in University Libraries. Library Management, 31(4/5): 253-266.

Baron, R. M., \& Kenny, D. A. 1986. The Moderator - Mediator Variable Distinction in Social Psychological Research: Conceptual, Strategic, and Statistical Consideration. Journal of Personality and Social Psychology, 51 (6): 11731182.

Bass, B. M. 1990. From Transactional to Transformational Leadership: Learning to Share Vision. Organizational Dynamics, 19-31.

Bass, B. M. 1997. Does the Transactional -Transformational Leadership Paradigm Transcend Organizational and National Boundaries? American Psychologist, 52 (2): 130-139.

Bernerth, J. B., Armenakis, A. A., Field, H. S., \& Walker, H. J. 2007. Justice, Cynicism, and Commitment: a Study of Important Organizational Change Variables. The Journal of Applied Behavioral Science, 43 (3): 303-326.

Bommer, W. H., Rich, G. A., \& Rubin, R. S. 2005. Changing Attitudes about Change: Longitudinal Effects of Transformational Leader Behavior on Employee Cynicism about Organizational Change. Journal of Organizational Behavior, 27 (7): 773-753.

Bono, J. E., \& Judge, T. A. 2003. Self-Concordance at Work: Toward Understanding the Motivational Effects of Transformational Leaders. Academy of Management Journal, 46 (5): 554-571.

Bolino, M. C., \& Turnley, W. H. 2008. Old Faces, New Places: Equity Theory in CrossCultural Context. Journal of Organizational Behavior, 29: 29-50.

Brown, M., \& Cregan, C. 2008. Organizational Change Cynicism: The Role of Employee Involvement. Human Resource Management Journal, 47 (4): 667686.

Cameron, K. S. 2008. Paradox in Positive Organizational Change. The Journal of Applied Behavioral Science, 44 (1): 7-24.

Camps, J., \& Rodriguez, H. 2011. Transformational Leadership, Learning, and Employability: Effects on Performance among Faculty Members. Personnel Review, 40 (4): 423-442.

Colquitt, J. A., Conlon, D. E., Wesson, M. J., Porter, C. O. L. H., \& Ng, K. Y. 2001. Justice at the Millennium: A Meta-Analytic Review of 25 Years of Organizational Justice Research. Journal of Applied Psychology, 86 (3): 425-445.

Cooper, D. R., \& Schindler, P. S. 2011. Business Research Method 11ed. New York: McGraw-Hill.

Cumming, T. G., \& Worley, C. G. 2005. Organization Development and Change: $8^{\text {th }}$ edition. Cincinnati, $\mathrm{OH}$ : Southwestern-College Publishing.

Dean, J. W., Branders, P., \& Dharwadkar, R. 1998. Organizational Cynicism. Academy of Management Review, 23: 341-352.

Dirks, K. T., \& Ferrin, D. L. 2001. The Role of Trust in Organizational Settings. Organization Science, 12 (4): 450-467.

Erdogan, B., \& Liden, R. C. 2006. Collectivism as a Moderator of Responses to Organizational Justice: Implication for Leader-Member Exchange and Integration. Journal of Organizational Behavior, 27: 1-17. 
Erwin, D. G., \& Garman, A. N. 2010. Resistance to Organizational Change: Linking Research and Practice. Leadership and Organization Development Journal, 31 (1): 39-56.

Felfe, J., \& Schyns, B. 2010. Followers' Personality and the Perception of Transformational Leadership : Further Evidence for the Similarity Hypothesis. British Journal of Management, 21: 393-410.

Ferres, N., \& Connel, J. 2004. Emotional Intelligence in Leaders: an Antidote for Cynicism Towards Change? Strategic Change, 13: 61-71.

Fleming, P., \& Spicer, A. 2003. Working at Cynical Distance: Implication for Power, Subjectivity, and Resistance. Organization Journal, 10 (1): 157-179.

Griffith, J. 2004. Relation of Principal Transformational Leadership to School Staff Job Satisfaction, Staff Turnover, and School Performance. Journal of Educational Administration, 42(3): 333-356.

Hair, J. F., Black, W. C., Babin, B. J., \& Anderson, R. E. 2010. Multivariate Data Analysis, $7^{\text {th }}$ Edition. Singapore: Simon \& Schuster Asia Pte, Ltd.

Ince, M., \& Turan, S. 2011. Organizational Cynicism as a Factor that Affect the Organizational Change in the Process of Globalization and an Application in Karaman's Public Institutions. European Journal of Economics, Finance and Administrative Science, 37: 104-121.

Ismail, K., Khurram, W., Hussain, T., \& Jafri, S. K. A. 2011. Perceptions for Transformational leadership, Followers' Psychological Capital and Intent to Leave in Pakistan: an Insight from Medical and Engineering Sector. Interdisciplinary Journal of Research in Business, 1 (8): 49-61.

Jones, D. A., \& Martens, M. L. 2009. The Mediating Role of Overall Fairness and The Moderating Role of Trust Certainty in Justice Criteria Relationships: The Formation and Use of Fairness Heuristics in the Workplace. Journal of Organizational Behavior, 30: 1025-1051.

Jordan, P. J. 2000. Dealing with Organizational Change: Can Emotional Intelligence Enhance Organizational Learning. International Journal of Organizational Behavior, 81: 456-471.

Kerlinger, F. N., \& Lee, H. B. 2000. Foundations of Behavioral Research 2nd. Harcourt College Publisher.

Kickul, J., Lester, S. W., \& Finki, J. 2002. Promise Breaking During Radical Organizational Change: Do Justice Interventions Make a Difference? Journal of Organizational Behavior, 23 (4): 469-488.

Kirkbride, P. 2006. Developing Transformational Leaders: The Full Range Leadership Model in Action. Industrial and Commercial Training, 38 (1): 2332.

Kwon, S. W., Kim, M. S., Kang, S. C., \& Kim, M. U. 2008. Employee Reactions to Gain Sharing Under Seniority Pay Systems: The Mediating Effect of Distributive, Procedural, and Interactional Justice. Human Resource Management Journal, 47 (4): 757-775.

Leithwood, K., \& Jantzi, D. 2000. The Effect if Transformational Leadership on Organizational Conditions and Student Engagement with School. Journal of Educational Administration, 38 (2): 112-129.

McClough, A. C., Rogelberg, S. G., Fisher, G. G., \& Bachiochi, P. D. 1998. Cynicism and The Quality of an Individual's Contribution to an Organizational Diagnostic Survey. Organization Development Journal, 16 (2): 31-42. 
Melkonian, T. 2004. Top Executives Reactions to Change: The Role of Justice and Exemplarity. International Studies of Management and Organizations, 344: 728.

Menon, S. T. 2001. Employee Empowerment: An Integrative Psychological Approach. Journal of Applied Psychology: An International Review, 50: 153-180.

Miller, C., Burke, L. M., \& Glick, W. H. 1998. Cognitive Diversity among Upper-Echelon Executive: Implication for Strategic Decision Processes. Strategic Management Journal, 191: 39-58.

Mishra, A. K., \& Spreitzer, G. M. 1998. Explaining How Survivors Respond to Downsizing: The Role of Trust, Empowerment, Justice and Work Redesign. Academy of Management Review, 23: 567-588.

Moormzn, R. H. 1991. Relationship Between Organizational Justice and Organizational Citizenship Behaviors: Do Fairness Perceptions Influence Employee Citizenship? Journal of Applied Psychology, 76 (6): 845-855.

Piderit, S. K. 2000. Rethinking Resistance and Recognizing Ambivalence: A Multidimensional View of Attitudes toward an Organizational Change. Academy of Management Review, 25 (4): 783-794.

Pieterse, A. D., Knippenberg, D. V., Schippers, M., \& Stam, D. 2010. Transformational and Transactional Leadership and Innovative Behavior: The Moderating Role of Psychological Empowerment. Journal of Organizational Behavior, 31: 609-623.

Pillai, R., Scandura, T. A., \& Williams, E. A. 1999. Leadership and Organizational Justice: Similarities and Differences Across Cultures. Journal of International Business Studies, 30 (4): 763-779.

Reardon, K. K., Reardon, K. J., \& Rowe, A. J. 1998. Leadership Style for The Five Stages of Radical Change. Acquisition Review Quarterly: 129-146.

Reichers, A. E., Wanous, J. P., \& Austin, J. T. 1997. Understanding and Managing Cynicism about Organizational Change. The Academy of Management Executive, 11 (1): 48-59.

Richardson, H. T., \& Vandenberg, R. J. 2005. Integrating Managerial Perceptions and Transformational Leadership into a Work-Unit Level Model of Employee Involvement. Journal of Organizational Behavior, 26 (5): 561-589.

Schein, E. H. 1967. Attitude Change during Management Education. Administrative Science Quarterly, 11 (4): 601-628.

Shamir, B., House, R. J., \& Arthur, M. B. 1993. The Motivational Effects of Charismatic Leadership: A Self-Concept Based Theory. Organization Science, 4 (4): 577594.

Simons, T., \& Roberson, Q. 2003. Why Managers Should Care about Fairness: The Effects of Aggregate Justice Perceptions on Organizational Outcomes. Journal of Applied Psychology, 88 (3): 432-443.

Stanley, D. J., Meyer, J. P., \& Topolnytsky, L. 2005. Employee Cynicism and Resistance to Organizational Change. Journal of Business and Psychology, 19 (4): 429459.

Thompson, R. C., Joseph, K. M., Bailey, L. L., Worley, J. A., \& William, C. A. 2000. Organizational Change: An Assessment of Trust and Cynicism. U.S. Department of Transportation: Federal Aviation Administration: 1-9.

Umpress, E. E., Labianca, G., Brass, D. J., Kass, E., \& Scholten, L. 2003. The Role of Instrumental and Expressive Social Ties in Employees' Perceptions of Organizational Justice. Organization Science, 14 (6): 738-753 
Vakola, M., Tsaousis, I., \& Nikolaou, I. 2004. The Role of Emotional Intelligence and Personality Variables on Attitudes Toward Organizational Change. Journal of Managerial Psychology, 19 (2): 88-110.

Vance, R. J., Brooks, S. M., \& Tesluk, P. E. 1996. Organizational Cynicism and Change. Working Paper, Pennsylvania State University, University Park.

Vugt, M. V., Hogan, R., \& Kaiser, R. B. 2008. Leadership, Followership, and Evolution. American Psychologist, 63 (3): 182-196.

Watt, J. D., \& Piotrowski, C. 2008. Organizational Change Cynicism: A Review of the Literature Intervention Strategies. Organizational Development Journal, 26 (3): 23-31.

Wanous, J. P., Reichers, A. E., \& Austin, J. T. 2000. Cynicism about Organizational Change: Measurement, Antecedents, and Correlates. Group Organization Management; 25: 132-153.

Warner, J. C., Hegtvedt, K. A., \& Roman, P. 2005. Procedural Justice, Distributive Justice: How Experiences With Downsizing Condition Their Impact on Organizational Commitment. Social Psychology Quarterly, 68 (1): 89-102

Worren, z., Ruddle, K., \& Moore, K. 1999. From Organizational Development to Change Management: The Emergence of a New Profession. Journal of Applied Behavioral Science, 353: 273-286.

Wu, C., Neubert, M. J., \& Yi, X. 2007. Transformational Leadership, Cohesion Perception and Employee Cynicism about Organizational Change. The Journal of Applied Behavioral Science, 43 (3): 327-351. 